\title{
Simplified Speed-Sensorless Vector Control for Induction Motors and Stability Analysis
}

\author{
Mineo Tsuji*a) Senior Member, Glanny M. Ch. Mangindaan* Student Member \\ Yurika Kunizaki* ${ }^{*}$ Student Member, Shin-ichi Hamasaki* ${ }^{*}$ Member
}

(Manuscript received April 3, 2013, revised Sep. 26, 2013)

\begin{abstract}
This paper presents a new simplified speed-sensorless vector control method for induction motors. The output voltage of the $d$-axis PI current controller with a decoupling control is used to compute the flux angle and to control the speed in correspondence with its reference. System stability is discussed by the root loci computed from a linear model. The effectiveness of the proposed method is demonstrated by nonlinear simulations and experiments.
\end{abstract}

Keywords: speed-sensorless vector control, induction motor, root loci, linear model, stability analysis

\section{Introduction}

Speed-sensorless vector control of induction motors (IM) allows high performance control of torque and speed and the system is widely used. Many model reference adaptive system (MRAS) based methods are studied. Representative speed estimation schemes use flux simulator ${ }^{(1)(2)}$, fullorder observer ${ }^{(3)(6)-(8)}$ reduced-order observer ${ }^{(10)}$, or slidingmode full-order observer ${ }^{(4)(5)(9)}$. Manipulated design of the observers can improve the stability of the sensorless system even at low speed regenerating operation. However, the configurations of these systems are relatively complicated. It is because the MRAS based methods need state observer and many PI controllers $(d-q$ currents, speed and speed estimation). On the other hand, some simplified speed sensorless vector control methods are proposed. Simplifying the system configuration by removing the current regulators is proposed $^{(11)}$, and the stability is improved by adding a flux stabilizing controller using derivative of magnetic current ${ }^{(12)}$. However, these papers have no information about the stability of regenerating mode. A sensorless method using the induced $d$ - and $q$-axis voltages obtained by a voltage model has been proposed ${ }^{(13)}$, and a similar method is applied to railway vehicle traction ${ }^{(14)}$. However, the stable region is not clear in these papers. Furthermore, a primary flux control method is proposed ${ }^{(15)}$ and the stability is improved at regenerating mode $^{(16)}$.

In this paper, we propose a new simplified speed-sensorless vector control method of IM based on rotor flux ${ }^{(18)(20)}$. By considering a flux vector obtained by a voltage model in which the derivative term is neglected and a flux vector of a current model, the flux angle is estimated so as to align these vectors. Since the output voltage of $d$-axis PI current controller is used for both the flux angle estimation and speed

a) Correspondence to: Mineo Tsuji. E-mail: mineo@nagasaki-u. ac.jp

* Graduate School of Engineering, Nagasaki University

1-14, Bunkyo-machi, Nagasaki 852-8521, Japan control ( $q$-axis voltage control), the system is simplified and stabilized at regenerating mode. This scheme is not reported in conventional simplified methods. A linear model of the proposed system is derived in state space equation. System stability is discussed by showing root loci of the linear model. By virtue of the stability analysis, we design the parameters of controller. Transient responses of the proposed system are demonstrated by nonlinear simulation and experiment.

\section{Proposed Method}

The $d-q$ voltage model and current model of the induction motor which are used for the derivation of proposed system are described by (1)-(4) as follows:

$$
\begin{aligned}
& \text { voltage model: } \\
& \begin{array}{r}
e_{s d}^{*}=\left(R_{s}^{*}+\sigma L_{s} p\right) i_{s d}^{*}-\omega^{*} \sigma L_{s} i_{s q}+\frac{M p}{L_{r}} \psi_{r d}^{v}-\frac{\omega^{*} M}{L_{r}} \psi_{r q}^{v} \\
\ldots \ldots \ldots \ldots \ldots \ldots \ldots(1)
\end{array} \\
& e_{s q}^{*}=\omega^{*} \sigma L_{s} i_{s d}^{*}+\left(R_{s}^{*}+\sigma L_{s} p\right) i_{s q}+\frac{\omega^{*} M}{L_{r}} \psi_{r d}^{v}+\frac{M p}{L_{r}} \psi_{r q}^{v} \\
& \ldots \ldots \ldots \ldots \ldots \ldots(2)
\end{aligned}
$$

current model:

$$
\begin{aligned}
& 0=-\frac{M}{\tau_{r}^{*}} i_{s d}^{*}+\left(\frac{1}{\tau_{r}^{*}}+p\right) \psi_{r d}^{*}-\left(\omega^{*}-\hat{\omega}_{r}\right) \psi_{r q}^{*} \ldots \ldots \\
& 0=-\frac{M}{\tau_{r}^{*}} i_{s q}+\left(\omega^{*}-\hat{\omega}_{r}\right) \psi_{r d}^{*}+\left(\frac{1}{\tau_{r}^{*}}+p\right) \psi_{r q}^{*} \ldots \ldots \\
& \text { where, } p=d / d t, \sigma=1-M^{2} /\left(L_{s} L_{r}\right), \tau_{r}^{*}=L_{r} / R_{r}^{*}
\end{aligned}
$$

The $\hat{\omega}_{r}$ is the estimated speed. We define the $d-q$ axis which rotates synchronously with the rotor flux of the current model so as to satisfy that $\psi_{r q}^{*}=0$ as shown in Fig. 1. By assuming that the $d$-axis current command $i_{s d}^{*}$ is constant, we obtain (5) and (6) from (3) and (4) respectively.

$$
\begin{aligned}
& \psi_{r d}^{*}=M i_{s d}^{*} \ldots \ldots \\
& \omega^{*}=\hat{\omega}_{r}+\omega_{e} \ldots \\
& \text { where, } \omega_{e}=\frac{i_{s q}}{\tau_{r}^{*} i_{s d}^{*}}
\end{aligned}
$$




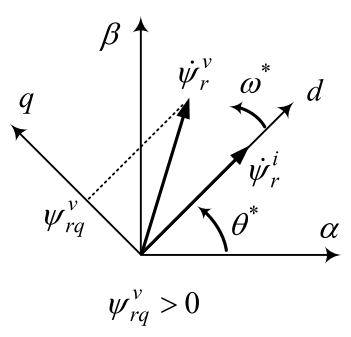

(a)

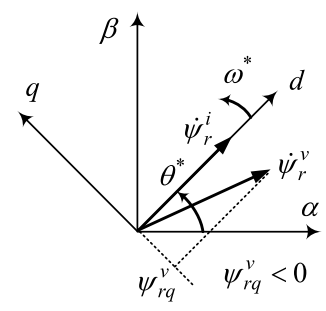

(b)
Fig. 1. The $d-q$ axis and rotor flux vectors

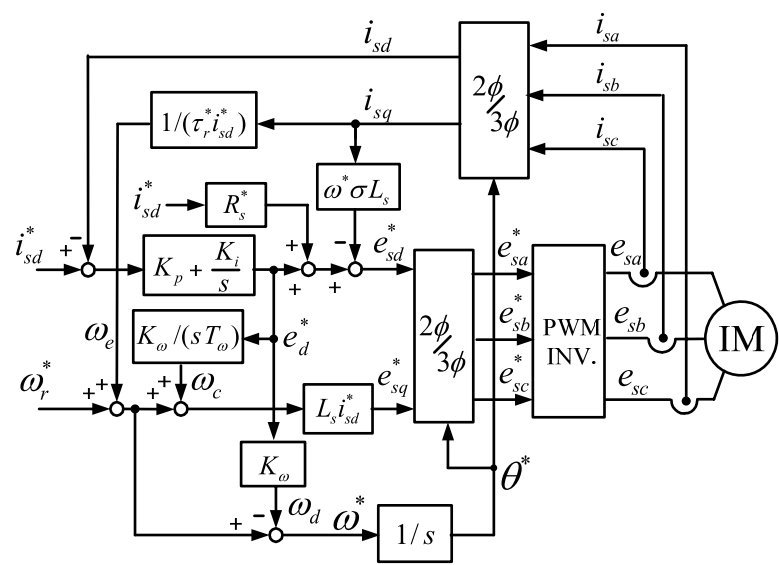

Fig. 2. Block diagram of proposed speed-sensorless system

By neglecting the derivative terms, the voltage model becomes:

$$
\begin{aligned}
& e_{s d}^{*}=R_{s}^{*} i_{s d}^{*}-\omega^{*} \sigma L_{s} i_{s q}-\frac{\omega^{*} M}{L_{r}} \psi_{r q}^{v} \ldots \ldots \ldots \ldots \ldots \ldots \\
& e_{s q}^{*}=\omega^{*} \sigma L_{s} i_{s d}^{*}+R_{s}^{*} i_{s q}+\frac{\omega^{*} M}{L_{r}} \psi_{r d}^{v} \ldots \ldots \ldots \ldots \ldots \ldots
\end{aligned}
$$

In Fig. 1, the rotor flux space vector obtained by the voltage model is denoted by $\dot{\psi}_{r}^{v}$ and that of current model is $\dot{\psi}_{r}^{i}$. When the rotor speed is unknown, the voltage model flux $\dot{\psi}_{r}^{v}$ can be used to estimate the flux direction. The flux angle $\theta^{*}$ is adjusted by changing $\omega^{*}$ such that the flux $\psi_{r q}^{v}$ becomes zero. When $\psi_{r q}^{v}>0$ and $\dot{\psi}_{r}^{v}$ is leading than $d$-axis as shown in (a), the controller must increase the value of $\omega^{*}$. When $\psi_{r q}^{v}<0$ and $\dot{\psi}_{r}^{v}$ is lagging than $d$-axis as shown in (b), the controller must decrease the value of $\omega^{*}$. We propose a speed sensorless vector control system as shown in Fig. 2.

We define the induced voltage as

$$
e_{d}^{*}=-\frac{\omega^{*} M}{L_{r}} \psi_{r q}^{v}
$$

Then, from (7) we have

$$
e_{s d}^{*}=R_{s}^{*} i_{s d}^{*}-\omega^{*} \sigma L_{s} i_{s q}+e_{d}^{*}
$$

The $e_{d}^{*}$ is obtained by the output of $d$-axis PI current controller with a decoupling control as shown in Fig. $2^{(18)}$. We estimate the $\omega^{*}$ by using (9) to converge the $q$-axis flux zero ${ }^{(17)}$ as follows:

$$
\omega^{*}=\omega_{r}^{*}+\omega_{e}-\omega_{d}
$$

where, $\omega_{d}=K_{\omega} e_{d}^{*}, K_{\omega}=\operatorname{sign}\left(\omega^{*}\right)\left|K_{\omega}\right|$.
The $\operatorname{sign}\left(\omega^{*}\right)$ is 1 when $\omega^{*}>0$ and -1 when $\omega^{*}<0$.

By assuming that $\psi_{r d}^{v}$ is equal to $\psi_{r d}^{*}$, we compute $e_{s q}^{*}$ as follows

$$
\begin{aligned}
& e_{s q}^{*}=\left(\omega_{r}^{*}+\omega_{e}+\omega_{c}\right) L_{s} i_{s d}^{*} \\
& \text { where, } \omega_{c}=\frac{K_{\omega}}{s T_{\omega}} e_{d}^{*} \ldots \ldots \ldots
\end{aligned}
$$

The term $\omega_{c}$ compensates the $q$-axis stator resistance voltage drop in steady-state condition. By the integral control of (13), $e_{d}^{*}$ becomes zero in steady-state, therefore, the actual speed $\omega_{r}$ is equal to the reference speed $\omega_{r}^{*}$ when motor constants are correct. From (6) and (11), we have

$$
\omega_{d}=\omega_{r}^{*}-\hat{\omega}_{r} \ldots \ldots \ldots \ldots \ldots \ldots \ldots \ldots \ldots \ldots \ldots \ldots \ldots \ldots \ldots \ldots
$$

Therefore, the speed control is accomplished by (13) even in transient state.

In proposed system of Fig. 2, any observer is not used and $d$-axis current controller (PI) and flux frequency controller (P) and speed controller (I) are used. Therefore, the proposed system is much simpler than conventional observer based systems.

\section{Stability Analysis}

To describe the IM shown in Fig. 2, we chose the $d$ - $q$ axis which rotates synchronously with $\theta^{*}$. Then, well-known induction motor $d-q$ model is obtained. In this paper, the following assumptions are made:

1) Voltage control is ideal, therefore

$$
e_{s d}=e_{s d}^{*}, \quad e_{s q}=e_{s q}^{*} .
$$

2) The machine constants of controller are equal to those of actual machine.

The state variable $e_{c d}$ is defined as

$$
p e_{c d}=K_{i}\left(i_{s d}^{*}-i_{s d}\right)
$$

The equation of motion is described as

$$
\frac{2}{P} J p \omega_{r}=\frac{P}{2} \frac{M}{L_{r}}\left(i_{s q} \psi_{r d}-i_{s d} \psi_{r q}\right)-T_{L} \ldots \ldots \cdots
$$

where, $P$ : number of poles, $T_{L}$ : load torque.

By using (9)-(13), (15)-(17), and the $d$ - $q$ model of IM $^{(17)}$, the following non-linear state equation is obtained.

$$
p \boldsymbol{x}=\boldsymbol{f}\left(\boldsymbol{x}, i_{s d}^{*}, \omega_{r}^{*}, T_{L}\right) .
$$

where,

$$
\boldsymbol{x}=\left[\begin{array}{lllllll}
i_{s d} & i_{s q} & \psi_{r d} & \psi_{r q} & \omega_{r} & e_{c d} & \omega_{c}
\end{array}\right]^{T}
$$

Transient responses are computed by solving (18).

Taking a small perturbation of state variables at steadystate operating point, a linear model of proposed system is derived from (18). A linear model of the proposed system is derived in form (Refer to the Appendix.)

$$
p \Delta \boldsymbol{x}=\boldsymbol{A} \Delta \boldsymbol{x}+\boldsymbol{B} \Delta \omega_{r}^{*}+\boldsymbol{B}_{L} \Delta T_{L}
$$

where, $\Delta \boldsymbol{x}=\left[\begin{array}{lllllll}\Delta i_{s d} & \Delta i_{s q} & \Delta \psi_{r d} & \Delta \psi_{r q} & \Delta \omega_{r} & \Delta e_{c d} & \Delta \omega_{c}\end{array}\right]^{T}$. System stability is discussed by using root loci by computing the eigenvalues of the matrix $\boldsymbol{A}$. We confirmed that the transient responses of linear model are close to those of the nonlinear model during small displacements about a steady 
state operating point ${ }^{(20)}$. Therefore the derivation of linear model is reliable.

System is stable when all eigenvalues of the matrix $\boldsymbol{A}$ of linear model (20) lie inside the left half of $s$-plane.

The $d$-axis PI current controller is designed as $K_{p}=14.7$, $K_{i}=3395$ having cut off frequency $1500 \mathrm{rad} / \mathrm{s}$. The control parameters $K_{\omega}$ and $T_{\omega}$ are studied by using the root loci. As the result explained below, we have selected $\left|K_{\omega}\right|=5.0$ and $T_{\omega}=0.05$ as designed parameters.

The constants of induction motor used for stability analysis are: number of poles $P=4$, stator resistant $R_{s}=1.54 \Omega$, rotor resistance $R_{r}=0.787 \Omega$, stator and rotor inductance $L_{s}=L_{r}$ $=0.115 \mathrm{H}$, mutual inductance $M=0.11 \mathrm{H}$, and moment of inertia including load $J=0.0126 \mathrm{~kg}-\mathrm{m}^{2}$.

Figure 3 shows the trajectories of dominant poles at speed command $50 \mathrm{~min}^{-1}$ for the change of slip speed $N_{s l}$. Slip speed $80 \mathrm{~min}^{-1}$ almost corresponds to the rated torque. Although the system is unstable at plugging region in which the slip speed is less than $-50 \mathrm{~min}^{-1}$, the system is stable at regenerating region when $-50 \mathrm{~min}^{-1}<N_{s l}<0 \mathrm{~min}^{-1}$.

When the speed commands are $100 \mathrm{~min}^{-1}, 1000 \mathrm{~min}^{-1}$ and $1500 \mathrm{~min}^{-1}$, the trajectories are shown in Fig. 4, Fig. 5 and Fig. 6 respectively. It is observed that the system is stable both in regenerating and in motoring operations. The roots move left side of $s$-plane and the system becomes more stable as the speed command increases.

Figures 7 and 8 shows the root loci when the gain $\left|K_{\omega}\right|=$ 2.0 at speed $100 \mathrm{~min}^{-1}$ and $1500 \mathrm{~min}^{-1}$ respectively. It is observed that the system becomes unstable (Fig. 7) or weakly damped (Fig. 8) in regenerating region when $K_{\omega}$ is small. It is noted that small value of $\left|K_{\omega}\right|$ can be relatively acceptable in motoring region.

Figure 9 shows the unstable region when $\left|K_{\omega}\right|=5.0$ and $T_{\omega}=0.05$ for the changes of speed command and slip speed. The shaded area means unstable region. The unstable region is observed in plugging region and very low speed motoring region. However, all regenerating region is stable.

Figure 10 shows the unstable region when $\left|K_{\omega}\right|=5.0$ and $T_{\omega}=0.2$. Although the large value of $T_{\omega}$ causes unstable region of regenerating operation, the stable region of motoring and plugging operations is expanded. So if we change the

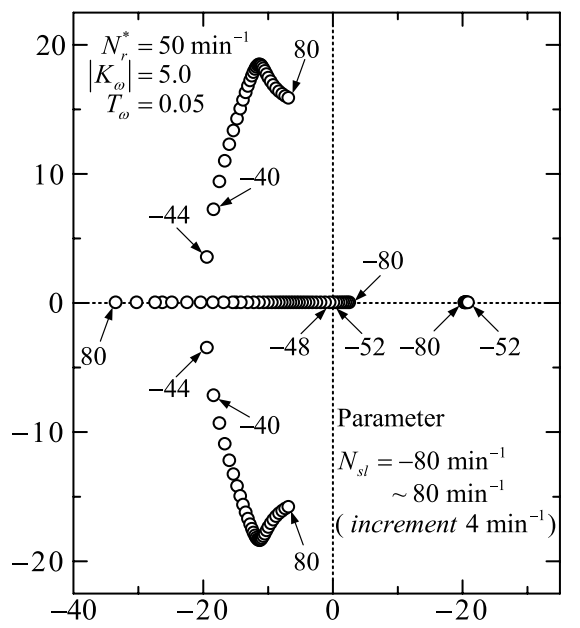

Fig. 3. Trajectories of poles at speed $N_{r}^{*}=50 \mathrm{~min}^{-1}$ for the change of slip speed with $\left|K_{\omega}\right|=5.0$ and $T_{\omega}=0.05$

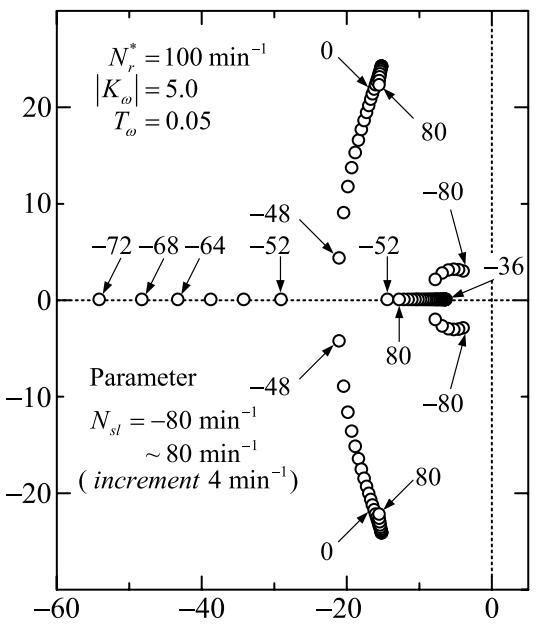

Fig. 4. Trajectories of poles at speed $N_{r}^{*}=100 \mathrm{~min}^{-1}$ for the change of slip speed with $\left|K_{\omega}\right|=5.0$ and $T_{\omega}=$ 0.05

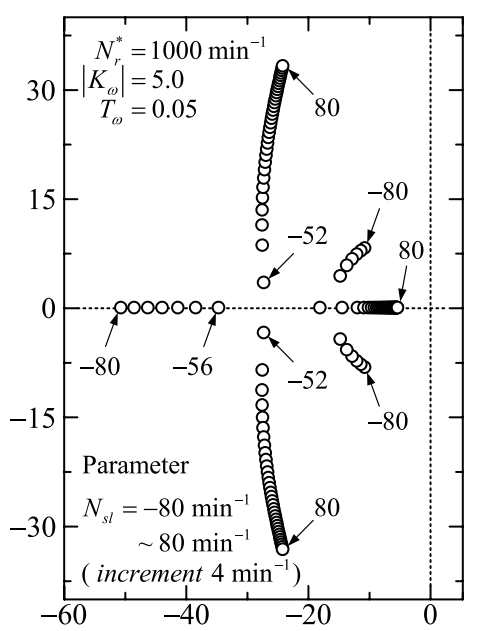

Fig. 5. Trajectories of poles at speed $N_{r}^{*}=1000 \mathrm{~min}^{-1}$ for the change of slip speed with $\left|K_{\omega}\right|=5.0$ and $T_{\omega}=$ 0.05

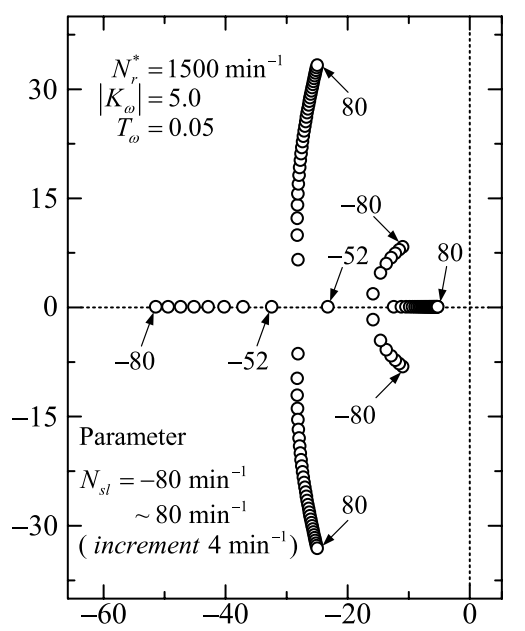

Fig. 6. Trajectories of poles at speed $N_{r}^{*}=1500 \mathrm{~min}^{-1}$ for the change of slip speed with $\left|K_{\omega}\right|=5.0$ and $T_{\omega}=$ 0.05 


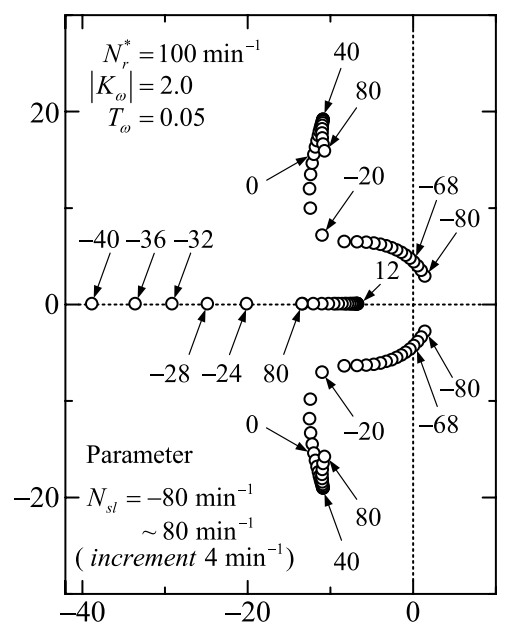

Fig. 7. Trajectories of poles at speed $N_{r}^{*}=100 \mathrm{~min}^{-1}$ for the change of slip speed with $\left|K_{\omega}\right|=2.0$ and $T_{\omega}=$ 0.05

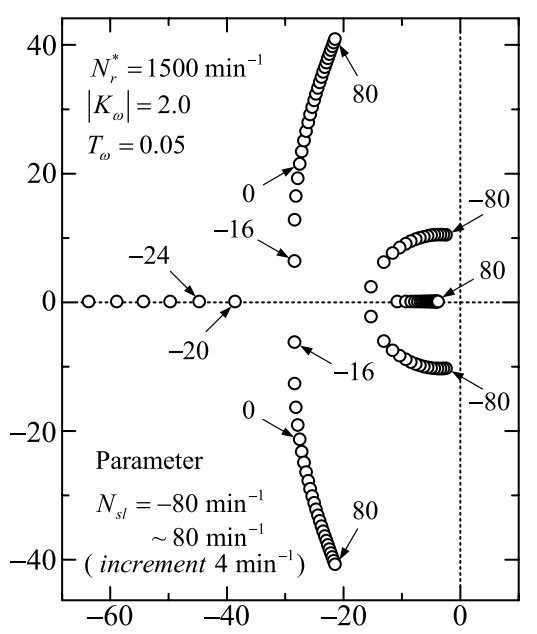

Fig. 8. Trajectories of poles at speed $N_{r}^{*}=1500 \mathrm{~min}^{-1}$ for the change of slip speed with $\left|K_{\omega}\right|=2.0$ and $T_{\omega}=$ 0.05

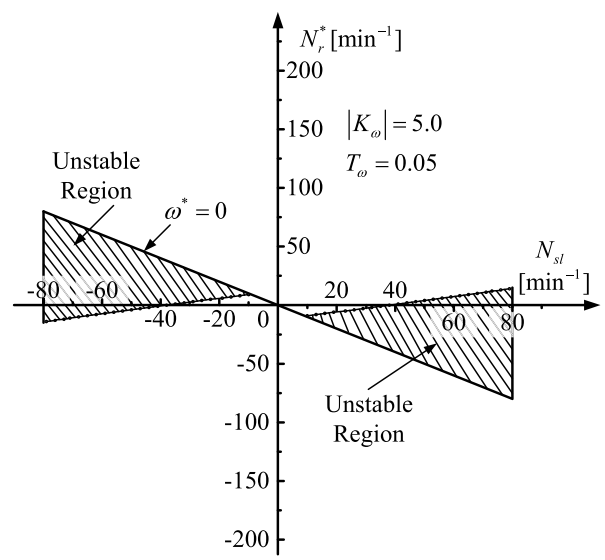

Fig. 9. Unstable region with parameters $\left|K_{\omega}\right|=5.0$ and $T_{\omega}=0.05$

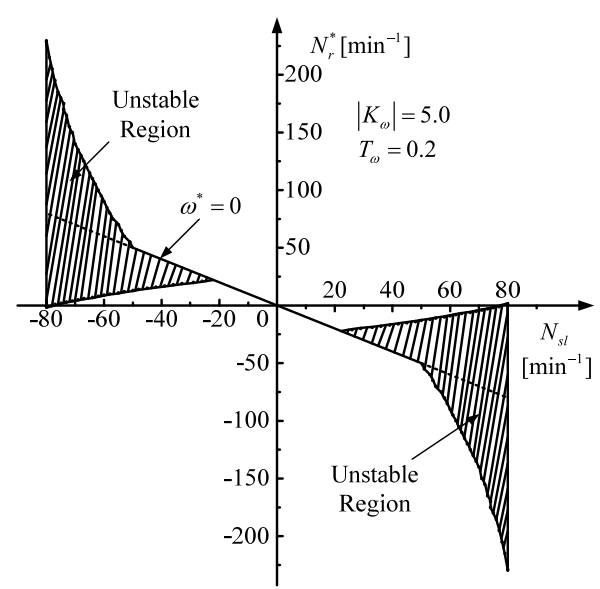

Fig. 10. Unstable region with parameters $\left|K_{\omega}\right|=5.0$ and $T_{\omega}=0.2$
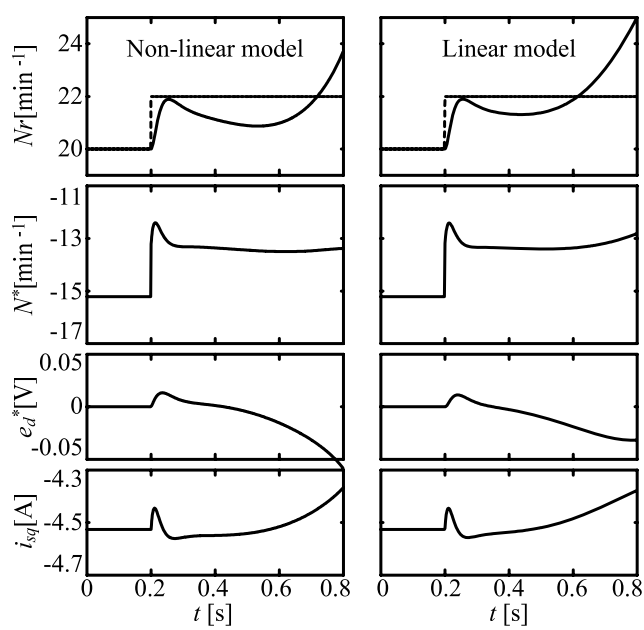

Fig. 11. Unstable transient responses with parameters $\left|K_{\omega}\right|=5.0, T_{\omega}=0.05$ and $T_{L}=-4.0 \mathrm{~N}-\mathrm{m}$ for the step change of speed command from $20 \mathrm{~min}^{-1}$ to $22 \mathrm{~min}^{-1}$

$\left|K_{\omega}\right|$ and $T_{\omega}$, the unstable region can be reduced.

As the results of stability analysis, large value of $\left|K_{\omega}\right|$ stabilize the system. Too small value of $T_{\omega}$ increases the unstable region in motoring mode ${ }^{(20)}$ and too large value of $T_{\omega}$ increases it in regenerating mode.

Figure 11 shows the transient responses when the system is operated at unstable region in Fig. 9 for the step change of speed command from $20 \mathrm{~min}^{-1}$ to $22 \mathrm{~min}^{-1}$ with parameters $\left|K_{\omega}\right|=5.0$ and $T_{\omega}=0.05$ and $T_{L}=-4.0 \mathrm{~N}-\mathrm{m}\left(N_{s l}=\right.$ $-35.2 \mathrm{~min}^{-1}$ at $t=0$ ). Both the non-linear model of (18) and the linear model of (20) have similar responses in short period after the step change of speed reference.

\section{Experimental Results}

The proposed control system is implemented by a DSP (TMS320C32)-based PWM inverter. Sampling period used in this system is $200 \mu \mathrm{s}$. Because of the dead time and the non-ideal features of IGBT influence on the output voltage of the inverter, a compensating algorithm is developed for the experimental system ${ }^{(17)}$. The tested induction machine is $1.5 \mathrm{~kW}$ and the constants have been described in chapter 3 .

Figure 12 shows the experimental results for the step 


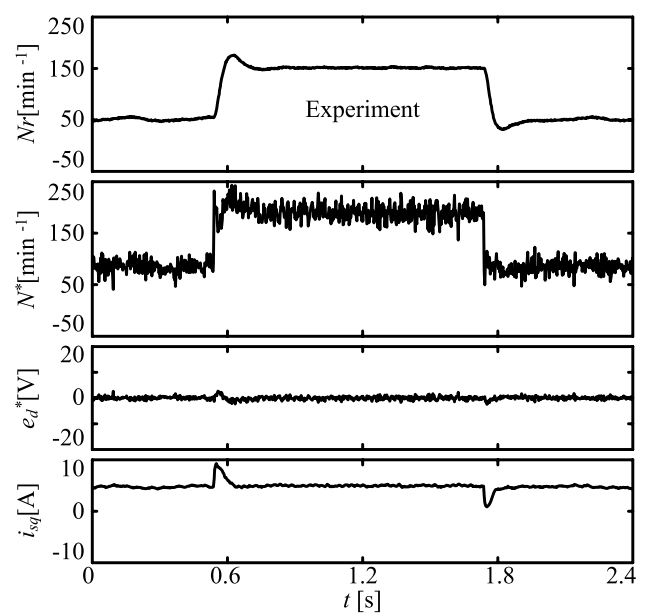

(a) $50 \rightarrow 150 \rightarrow 50 \mathrm{~min}^{-1}$

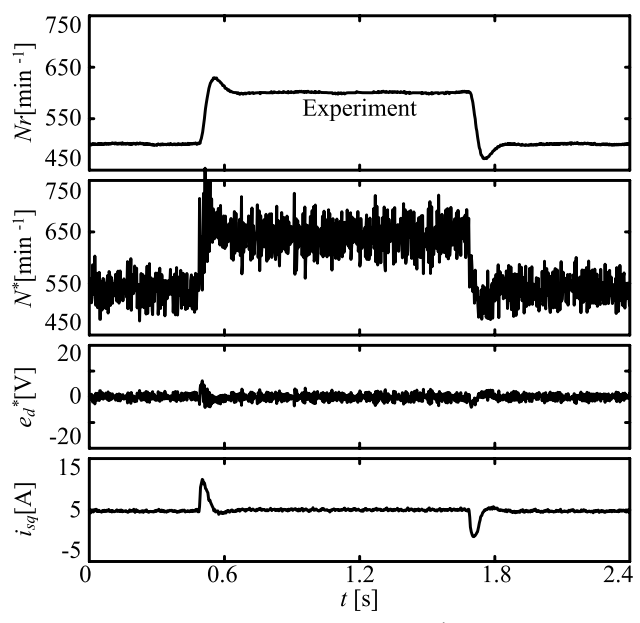

(b) $500 \rightarrow 600 \rightarrow 500 \mathrm{~min}^{-1}$

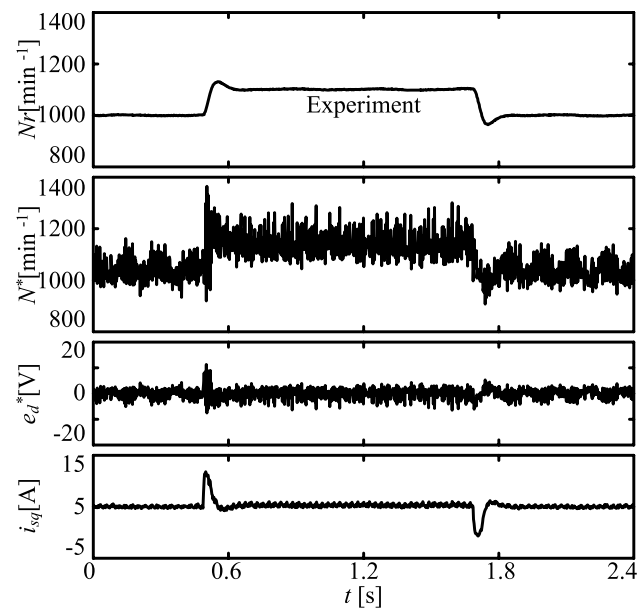

(c) $1000 \rightarrow 1100 \rightarrow 1000 \mathrm{~min}^{-1}$

Fig. 12. Transient responses for the step change of speed command. (Motoring operation $\left|K_{\omega}\right|=5.0 ; T_{\omega}=$ $\left.0.05 ; T_{L}=4.0 \mathrm{~N}-\mathrm{m}\right)$

change of the speed command $N_{r}^{*}$ in motoring operations. In case (a), $N_{r}^{*}$ is stepped from $50 \mathrm{~min}^{-1}$ to $150 \mathrm{~min}^{-1}$ and then down to $50 \mathrm{~min}^{-1}$. In cases (b) and (c), the speed commands are similarly stepped as $500 \rightarrow 600 \rightarrow 500 \mathrm{~min}^{-1}$ and $1000 \rightarrow 1100 \rightarrow 1000 \mathrm{~min}^{-1}$ respectively. $N_{r}$ is actual motor speed $\left(\omega_{r}\right)$ and $N^{*}$ is synchronous speed $\left(\omega^{*}\right)$. The control parameters are set as $\left|K_{\omega}\right|=5.0$ and $T_{\omega}=0.05$. The load

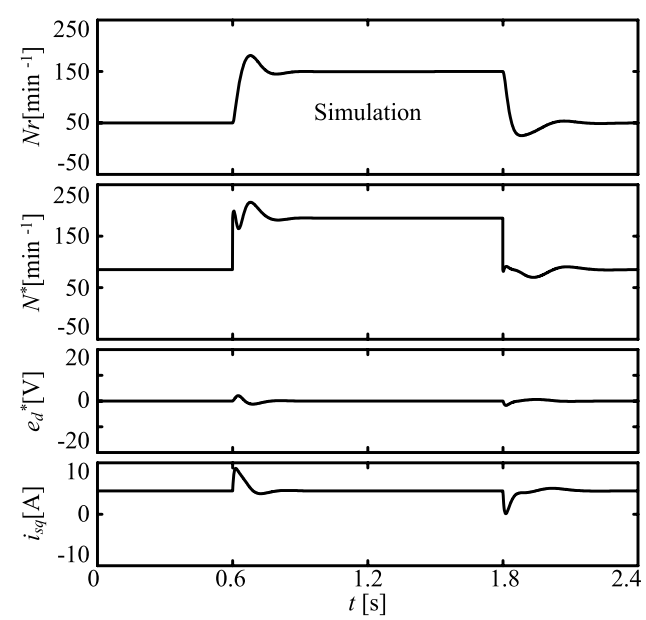

(a) $50 \rightarrow 150 \rightarrow 50 \mathrm{~min}^{-1}$

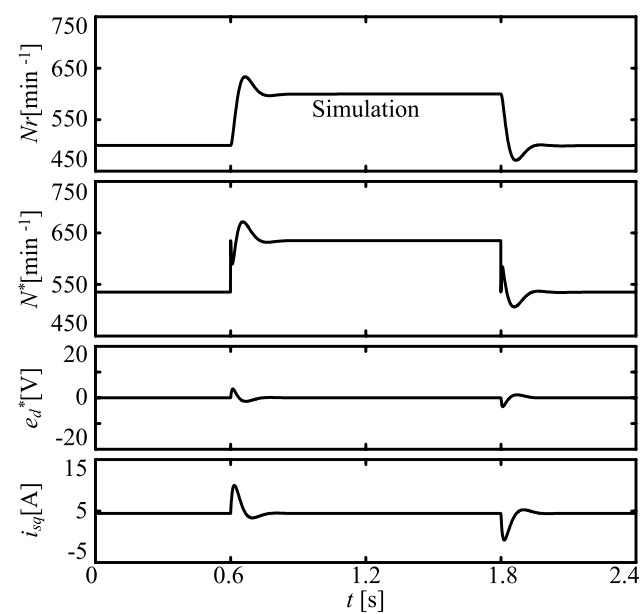

(b) $500 \rightarrow 600 \rightarrow 500 \mathrm{~min}^{-1}$

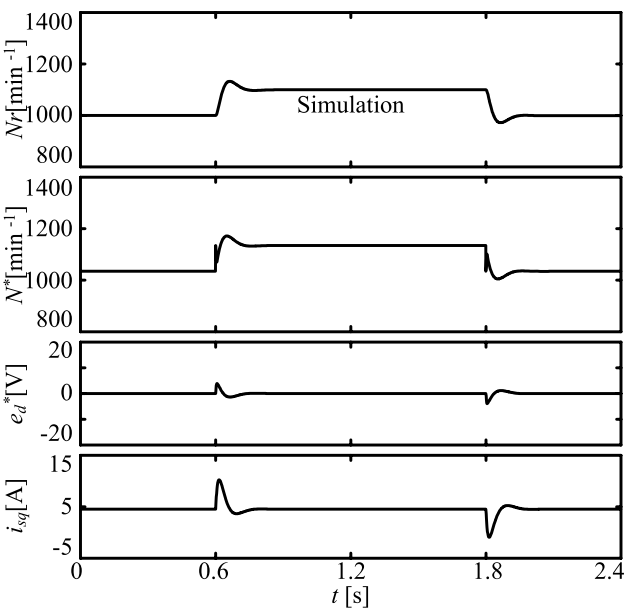

(c) $1000 \rightarrow 1100 \rightarrow 1000 \mathrm{~min}^{-1}$

Fig. 13. Transient responses for the step change of speed command. (Motoring operation $\left|K_{\omega}\right|=5.0 ; T_{\omega}=$ $\left.0.05 ; T_{L}=4.0 \mathrm{~N}-\mathrm{m}\right)$

torque $T_{L}$ is set to $4.0 \mathrm{~N}$-m (half of rated torque) by a DC generator connected to IM. In any cases, quick responses of $N_{r}$ are obtained and the changes of torque current $i_{s q}$ are similar to those of vector control system with speed sensor. The non-linear simulation results computed by (18) are shown in Fig. 13. Figures 13(a), (b) and (c) corresponds to Figs. 12(a), (b) and (c) respectively. The experimental results agree well 


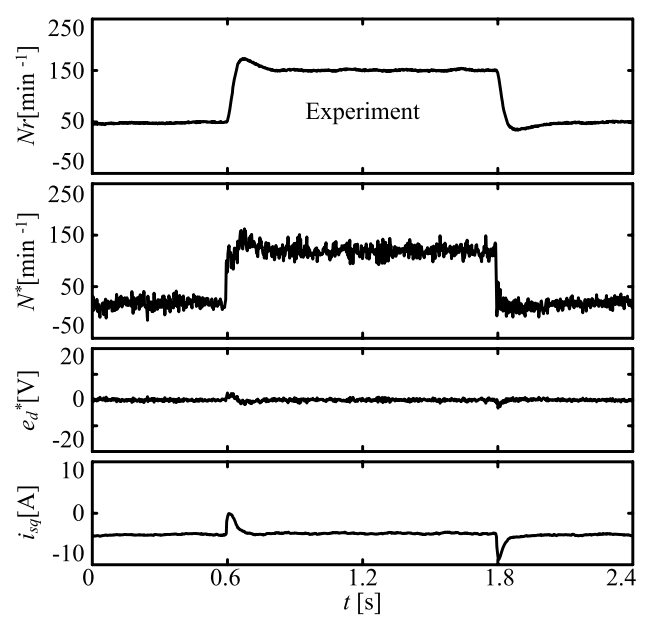

(a) $50 \rightarrow 150 \rightarrow 50 \mathrm{~min}^{-1}$

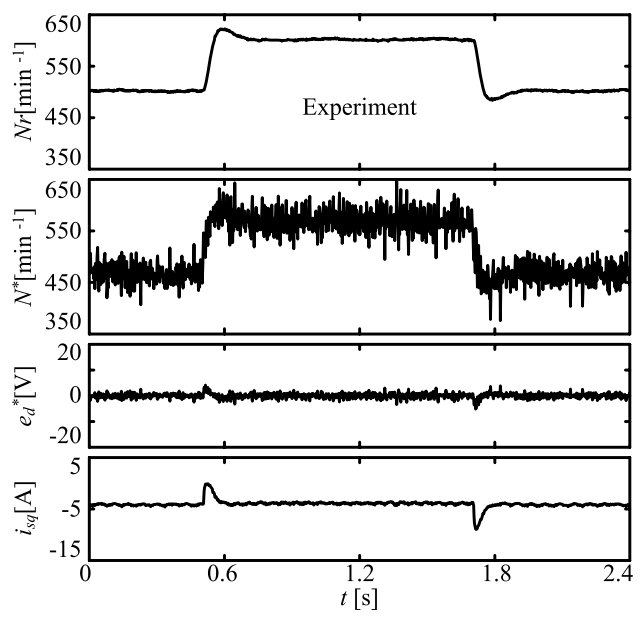

(b) $500 \rightarrow 600 \rightarrow 500 \mathrm{~min}^{-1}$

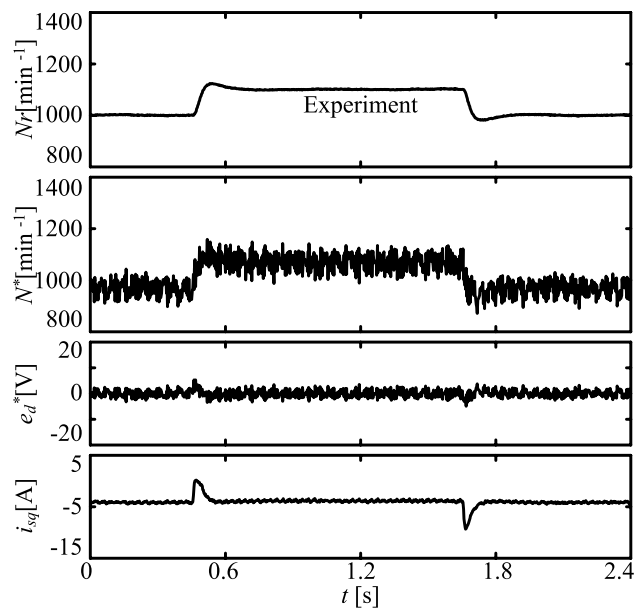

(c) $1000 \rightarrow 1100 \rightarrow 1000 \mathrm{~min}^{-1}$

Fig. 14. Transient responses for the step change of speed command (Regenerating operation $\left|K_{\omega}\right|=5.0 ; T_{\omega}$ $\left.=0.05 ; T_{L}=-4.0 \mathrm{~N}-\mathrm{m}\right)$

with the computed results except for high frequency ripples. The high frequency ripples of $N^{*}$ and $e_{d}^{*}$ are caused by PWM voltage control in experimental system. However, since the flux angle $\theta^{*}$ is obtained by integrating $\omega^{*}$, the actual rotor speed has little ripples.

Figures 14 and 15 show the experimental results and the non-linear simulation results in regenerating operations re-

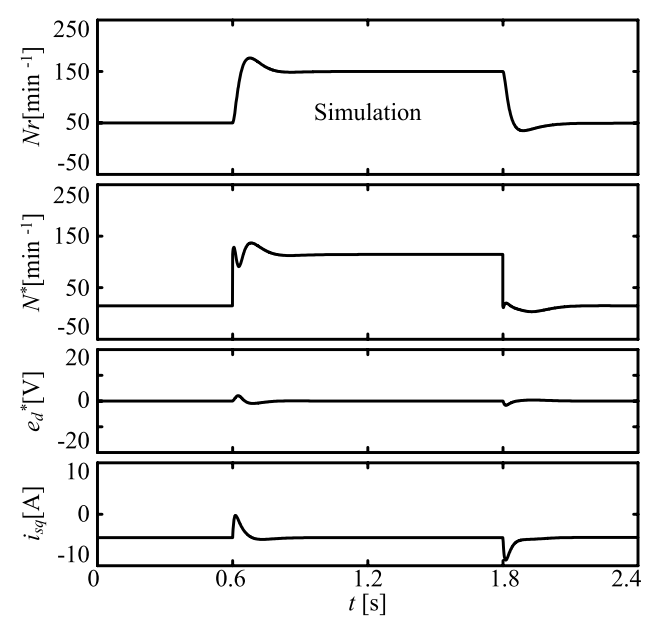

(a) $50 \rightarrow 150 \rightarrow 50 \mathrm{~min}^{-1}$
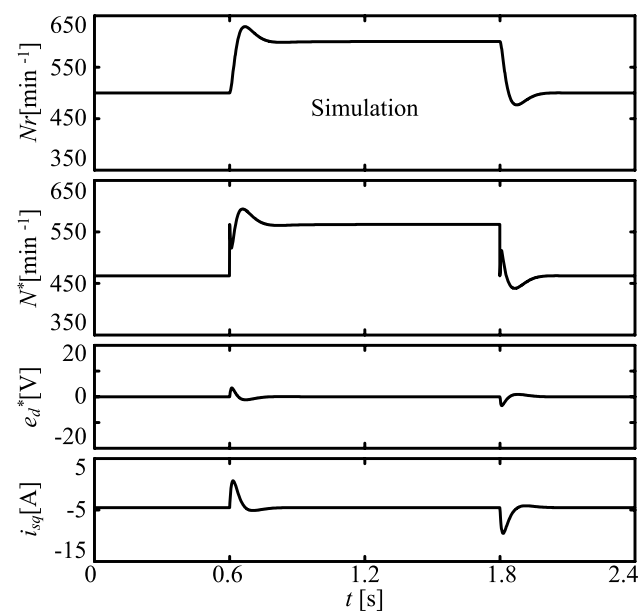

(b) $500 \rightarrow 600 \rightarrow 500 \mathrm{~min}^{-1}$

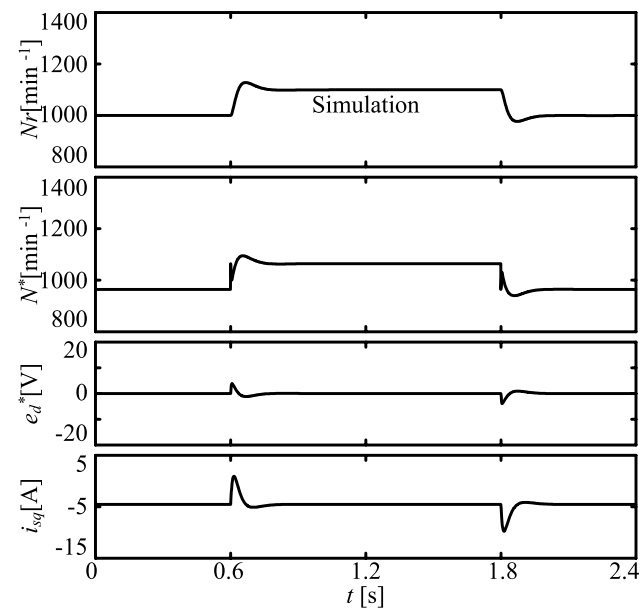

(c) $1000 \rightarrow 1100 \rightarrow 1000 \mathrm{~min}^{-1}$

Fig. 15. Transient responses for the step change of speed command (Regenerating operation $\left|K_{\omega}\right|=5.0 ; T_{\omega}$ $\left.=0.05 ; T_{L}=-4.0 \mathrm{~N}-\mathrm{m}\right)$

spectively. Same change of speed commands are tested under the load torque $T_{L}=-4.0 \mathrm{~N}-\mathrm{m}$. In any cases, quick responses of $N_{r}$ are obtained. The experimental results agree well with the computed results too. The high frequency ripples of $N^{*}$ in Fig. 14(c) are smaller than those in Fig. 12(c). The reason for this difference can be considered that the amplitude modulation ratio of regenerating operation is smaller if the voltage 
control has allowance under limited DC-bus voltage; the distortion of stator currents is reduced. The larger we choose the gain $\left|K_{\omega}\right|$, the larger high frequency ripples of $N^{*}$ are induced. From this point, we have selected the gain $\left|K_{\omega}\right|$ to 5.0 .

\section{Conclusions}

The conclusions drawn from this study are summarized as follows:

(1) We have proposed a new simplified speed-sensorless vector control method of IM.

(2) The flux angle computation and the torque and speed control are realized by using the output voltage of $d$ axis PI current controller with a decoupling control.

(3) A linear model is derived and the root loci obtained the model is used to design the control parameters.

(4) It is demonstrated that the proposed system can realize stable operation in both motoring and regenerating modes by the result of root loci.

(5) The experimental results agree with those of nonlinear simulation and the usefulness of proposed method is verified.

\section{References}

(1) C. Schauder: "Adaptive speed identification for vector control of induction motors without rotational transducers", IEEE Trans. Ind. Appl., Vol.28, No.5, pp.1054-1061 (1992)

( 2 ) H. Tajima and Y. Hori: "Speed sensorless field-orientation control of the induction machine", IEEE Trans. Ind. Appl., Vol.29, No.1, pp.175-180 (1993)

( 3 ) H. Kubota, K. Matsuse, and T. Nakano: "DSP-based speed adaptive flux observer of induction motor", IEEE Trans. Ind. Appl., Vol.29, No.2, pp.344-348 (1993)

( 4 ) M. Tursini, R. Petrella, and F. Parasiliti: "Adaptive sliding-mode observer for speed sensorless control of induction motors", IEEE Trans. Ind. Appl., Vol.36, No.5, pp.1380-1387 (2000)

( 5 ) T. Hamajima, M. Hasegawa, S. Doki, and S. Okuma: "Sensorless vector control of induction motor with stator resistance identification based on augmented error", Proc. of Power Conversion Conf. (PCC-Osaka), pp.504-509 (2002)

( 6 ) S. Suwankawin and S. Sangwongwanich: "A speed-sensorless IM drive with decoupling control and stability analysis of speed estimation", IEEE Trans. Ind. Electron., Vol.49, No.2, pp.444-455 (2002)

( 7 ) M. Hinkkanen: "Analysis and design of full-order flux observers for sensorless induction motors", IEEE Trans. Ind. Electron., Vol.51, No.5, pp.1033$1040(2004)$

( 8 ) M. Saejia and S. Sangwongwanich: "Averaging analysis approach for stability analysis of speed-sensorless induction motor drives with stator resistance estimation", IEEE Trans. Ind. Electron., Vol.53, No.1, pp.162-177 (2006)

( 9 ) C. Lascu, I. Boldea, and F. Blaabjerg: "A class of speed-sensorless slidingmode observers for high-performance induction motor drives", IEEE Trans. Ind. Electron., Vol.56, No.9, pp.3394-3403 (2009)

(10) M. Hinkkanen, L. Harnefors, and J. Luomi: "Reduced-order flux observer with stator-resistance adaptation for speed sensorless induction motor drives", IEEE Trans. Power Electron., Vol.25, No.5, pp.1173-1183 (2010)

(11) T. Okuyama, N. Fujimoto, and H. Fujii: "Simplified vector control system without speed and voltage sensors - effects of setting errors in control parameters and their compensation -", Trans. IEE Japan, Vol.110-D, No.5, pp.477-486 (1990) (in Japanese)

(12) S. Ishida, T. Endo, H. Fujii, H. Tomita, and N. Fujimoto: "Sensorless vector control with quick response for general purpose inverters", Proc. of Power Conversion Conf. (PCC-Yokohama), pp.467-472 (1993)

(13) H. Tajima, Y. Matsumoto, H. Umida, and M. Kawano: "Speed sensorless vector control method for an industrial drive system", Proc. of International Power Electronics Conference (IPEC-Yokohama), pp.1034-1039 (1995)

(14) K. Kondo and K. Yuki: "Study on an application of induction motor speed sensorless vector control to railway vehicle traction", Trans. IEE Japan, Vol.125-D, pp.1-8 (2005) (in Japanese)

(15) N. Yamamura, K. Aiba, and Y. Tsunehiro: "Primary flux control for induc- tion motor drive", Trans. IEE Japan, Vol.113-D, No.7, pp.859-864 (1993) (in Japanese)

(16) N. Yamamura, I. Yasuoka, N. Nanato, and Y. Tsunehiro: "A method for improving the performance characteristics of induction motor with primary flux control", Trans. IEE Japan, Vol.119-D, No.3, pp.371-376 (1999) (in Japanese)

(17) M. Tsuji, S. Chen, K. Izumi, and E. Yamada: "A sensorless vector control system for induction motors using $q$-axis flux with stator resistance identification", IEEE Trans. Ind. Electron., Vol.48, No.1, pp.185-194 (2001)

(18) M. Tsuji, R. Hashimoto, and S. Hamasaki: "A simple speed sensorless vector control of induction motor using $q$-axis flux", The Papers of Technical Meeting IEE Japan, RM-11-130, pp.31-36 (2011) (in Japanese)

(19) M. Tsuji, K. Kojima, G.M.Ch. Mangindaan, D. Akafuji, and S. Hamasaki: "Stability study of a permanent magnet synchronous motor sensorless vector control system based on extended EMF model", IEEJ Journal of Ind. Appl., Vol.1, No.3, pp.148-154 (2012)

(20) M. Tsuji, G.M.C. Mangindaan, Y. Kunizaki, R. Hashimoto, and S. Hamasaki: "A new simplified sensorless speed control of induction motor using $D$-axis voltage", Proc. of The $15^{\text {th }}$ International Conference on Electrical Machines and Systems (ICEMS), 6 pages (2012)

\section{Appendix}

$$
\begin{aligned}
& -a_{1}-\frac{K_{P}}{\sigma L_{s}} \quad 0 \quad \frac{M}{\sigma L_{s} L_{r} \tau_{r}} \\
& -\omega^{*}-i_{s d} K_{\omega} K_{P}-a_{1}+\frac{1}{\sigma \tau_{r}^{*}}-\frac{1}{\tau_{r}^{*}}-\frac{M \omega_{r}}{\sigma L_{s} L_{r}} \\
& \frac{M}{\tau_{r}}+\psi_{r q} K_{\omega} K_{P} \quad \frac{\psi_{r q}}{\tau_{r}^{*} i_{s d}^{*}} \quad-\frac{1}{\tau_{r}} \\
& -\psi_{r d} K_{\omega} K_{P} \\
& \boldsymbol{A}= \\
& -a_{2} \psi_{r q} \\
& \frac{M}{\tau_{r}}-\frac{\psi_{r d}}{\tau_{r}^{*} i_{s d}^{*}} \\
& \omega_{r}-\omega^{*} \\
& a_{2} \psi_{r d} \\
& a_{2} i_{s q} \\
& \begin{array}{c}
-K_{i} \\
-\frac{K_{\omega} K_{P}}{T_{\omega}}
\end{array} \\
& 0 \\
& 0 \\
& 0 \\
& \frac{M \omega_{r}}{\sigma L_{s} L_{r}} \quad \frac{M \psi_{r q}}{\sigma L_{s} L_{r}} \quad \frac{1}{\sigma L_{s}} \\
& \frac{M}{\sigma L_{s} L_{r} \tau_{r}} \quad-\frac{M \psi_{r d}}{\sigma L_{s} L_{r}} \quad i_{s d} K_{\omega} \quad \frac{i_{s d}^{*}}{\sigma} \\
& \begin{array}{llll}
\omega^{*}-\omega_{r} & -\psi_{r q} & -\psi_{r q} K_{\omega} & 0
\end{array} \\
& * \\
& \begin{array}{cccc}
-\frac{1}{\tau_{r}} & \psi_{r d} & \psi_{r d} K_{\omega} & 0 \\
-a_{2} i_{s d} & 0 & 0 & 0 \\
0 & 0 & 0 & 0 \\
0 & 0 & \frac{K_{\omega}}{T_{\omega}} & 0
\end{array}
\end{aligned}
$$

$a_{1}=\frac{R_{s}}{\sigma L_{s}}+\frac{M^{2}}{\sigma L_{s} L_{r} \tau_{r}}, \quad a_{2}=\frac{M P^{2}}{4 J L_{r}}$

$$
\boldsymbol{B}=\left[\begin{array}{c}
0 \\
i_{s d}^{*}-i_{s d} \\
\sigma \psi_{r q} \\
-\psi_{r d} \\
0 \\
0 \\
0
\end{array}\right], \quad \boldsymbol{B}_{L}=\left[\begin{array}{c}
0 \\
0 \\
0 \\
0 \\
-\frac{P}{2 J} \\
0 \\
0
\end{array}\right]
$$


Mineo Tsuji (Senior Member) was born in December 1953. He re-

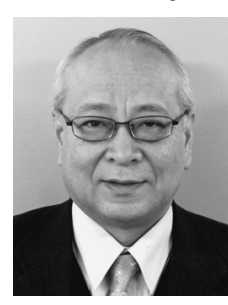
ceived the Ph.D. degree from Kyushu University in March 1981 in electrical engineering, became a lecturer at Nagasaki University in April 1981 and became a Professor in July 2001 in the Division of Electrical Engineering and Computer Science, Graduate School of Engineering, Nagasaki University. His current interests are control of $\mathrm{AC}$ machines and electrical power systems. Dr. Tsuji is a member of IEEE. He received a Prize Paper Award from the IEEJ in 1998.

Glanny M Ch Mangindaan (Student Member) was born in March

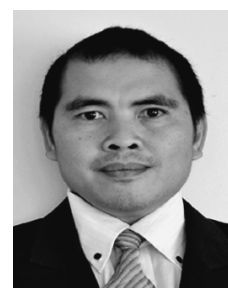
1974. He received the B.Eng. degree in electrical engineering from Sam Ratulangi University in 2000 and M.Eng. degree in electrical engineering from Sepuluh Nopember Institute of Technology in 2008. He became a lecturer in Division of Electrical Engineering at Sam Ratulangi University in December 2002. $\mathrm{He}$ has entered as Ph.D. course in Nagasaki University Graduate School of Engineering in 2012. His research interest is about the speed sensorless vector

control of AC motors.
Yurika Kunizaki (Student Member) was born in December 1989.

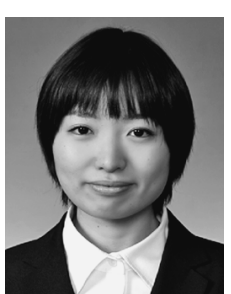
She received the B.S. degree in electrical engineering from Nagasaki University in 2012. Since same year she has entered a master's course of Graduate School of Engineering in Nagasaki University. Her research interest is about the speed sensorless vector control of Induction motors.

Shin-ichi Hamasaki (Member) was born in October, 1975. He re-

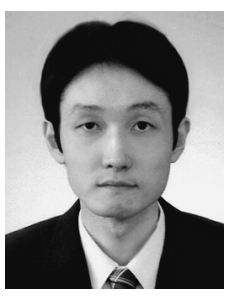
ceived the B.E. and M.E. and Ph.D. degrees in electrical engineering from Yokohama National University in 1998, 2000 and 2003 respectively. From 2003 to 2007, he was a Research Associate in the Department of Electrical and Electronic Engineering, Nagasaki University. Since April 2007, he has been an Assistant Professor in the Division of Electrical Engineering and Computer Science, Graduate School of Engineering, Nagasaki University. His current research interests are control of multilevel converter, power conditioning systems and machine drives. He is a member of IEEE. 